\title{
CARACTERIZAÇÃO MORFOAGRONÔMICA DE ACESSOS DE PHYSALIS ANGULATA L.
}

\author{
$\underline{\text { André Pinto Lima }}{ }^{1}$; Adriana Rodrigues Passos ${ }^{2}$; Hortência Kardec da Silva ${ }^{3}$ \\ 1.Bolsista CNPQ, Graduando em Agronomia, Universidade Estadual de Feira de Santana, e-mail: \\ andre8fs@hotmail.com \\ 2. Professora Adjunta, Orientadora, Departamento de Ciências Biológicas, Universidade Estadual de Feira de \\ Santana e-mail: adrianarpassos@yahoo.com.brhortencia \\ 3. Mestranda em Recurso Genético Vegetal, Co-orientadora, Departamento de Ciências Biológicas, \\ Universidade Estadual de Feira de Santana, e-mail: hortenciakardec@ hotmail.com
}

PALAVRAS-CHAVE: Divergência genética; Dissimilaridade; Seleção.

\section{INTRODUÇÃO}

Physalis angulata L. possui potencialidades que passam pelos setores econômicos, farmacológicos e nutracêuticos, o que a torna uma cultura com grande potencial a ser explorada, mas a carência de informações dificulta o avanço nas pesquisas em recursos genéticos e melhoramento dessa espécie. As pesquisas em recursos genéticos demandam uma grande carga de tarefas essenciais, de tal modo que necessitam de um considerável suporte financeiro e, principalmente exige continuidade (NASS et al., 2001). As dificuldades, existentes, nas atividades com recursos genéticos vegetais e nos programas de melhoramento são evidentes. Assim, é de fundamental importância ao iniciar um programa de melhoramento genético de alguma cultura conhecer a diversidade genética existente, podendo conhecer de maneira mais eficaz as variabilidades genéticas (PEREIRA; PEREIRA, 2006).

A caracterização morfológica é frequentemente a forma mais acessível de quantificar a diversidade genética (SINGH et al., 1991). Essa atividade consiste em fornecer uma série de informações a respeito da variabilidade genética de cada amostra estudada, tornando possível o conhecimento do germoplasma (DAROS et al., 2002). Já a caracterização agronômica tem como base avaliar características desejáveis pelo agricultor e que satisfaçam o mercado consumidor (FABRI, 2009). A caracterização morfoagronômica é realizada com base em caracteres que sejam de fácil detecção e mensuração, possuam alta herdabilidade e que sofram pouca influência ambiental (COSTA et al., 2009).

Portanto, o presente trabalho teve por objetivo caracterizar a variabilidade genética de acessos de Physalis angulata L., por meio de descritores morfoagronômicos.

\section{METODOLOGIA}

O experimento foi conduzido no campo experimental e Laboratório de Biologia Molecular (LAGEM) da Unidade Experimental Horto Florestal, pertencente à Universidade Estadual de Feira de Santana (UEFS) na região do semiárido da Bahia, cujas coordenadas geográficas são $12^{\circ} 16^{\prime}$ latitude sul, $38^{\circ} 58^{\prime}$ longitude oeste e $257 \mathrm{~m}$ de altitude. A temperatura média anual é de $23,5^{\circ} \mathrm{C}$, tendo como temperatura de $28,2^{\circ} \mathrm{C}$ e $19,6^{\circ} \mathrm{C}$ para máxima e mínima, respectivamente.

Foram utilizados 10 acessos oriundos de progênies com três ciclos de autofecundação. O experimento foi conduzido em fevereiro a maio de 2017, em blocos ao acaso, com três repetições e parcela constituída por cinco plantas. Foram avaliadas as características altura da planta $(\mathrm{AP})$, em $\mathrm{cm}$, número de ramificações $(\mathrm{NR})$, número de frutos por planta (NFP), diâmetro do caule (DC), em mm, peso de fruto (PF), em g, diâmetro transversal do fruto (DTF), em mm, diâmetro longitudinal do fruto (DLF), em mm, e sólidos solúveis (SS) em ${ }^{\circ}$ Brix.

$\mathrm{Na}$ análise da divergência genética foram empregados métodos multivariados, onde foram aplicadas técnicas de agrupamento. Foi utilizada a distância generalizada de 
Mahalanobis como medida de dissimilaridade, a partir da qual se realizou o agrupamento dos diferentes genótipos por meio do método hierárquico UPGMA e de otimização proposto por Tocher. As análises genético-estatísticas foram realizadas com o auxílio do software GENES (CRUZ, 2008). No método UPGMA realizou-se a validação dos agrupamentos, determinada pelo coeficiente de correlação cofenético, de acordo com Sokal e Rohlf (1962). A significância dos coeficientes de correlação cofenético foi calculado pelo teste de Mantel com 1000 permutações (MANTEL, 1967). O ponto de corte foi definido pelo método de Mojena (1977), obtido com o auxílio do pacote "NbClust" do programa computacional R (CHARRARD et al., 2014) e a contribuição relativa dos caracteres para a divergência genética foi determinada utilizando o critério proposto por Singh (1981).

Foi realizada a análise de variância e as médias obtidas foram agrupadas pelo teste de Scott-Knott a 5\% de probabilidade. Essas análises genético-estatísticas foram realizadas com o auxílio do software GENES (CRUZ, 2008).

\section{RESULTADOS E DISCUSSÃO}

A análise de variância demonstrou que não houve diferença significativa $(\mathrm{P}<0,05)$ para a maioria das características, com exceção do peso do fruto $(\mathrm{PF})$, levando a formação de três grupos, com superioridade do acesso sete em relação aos demais acessos.

A análise de agrupamento pelo método Tocher baseado na distância generalizada de Mahalanobis reuniu os 10 acessos de Physalis angulata em oito grupos distintos, dos quais o grupo I ordenou três acessos (30\% do total), e os demais grupos foram formados por apenas um acesso (Tabela 1).

Vasconcelos et al. (2007) caracteriza este método de agrupamento por formar grupos com apenas um acesso no caso dos genótipos com maior dissimilaridade, pelo fato do agrupamento sofrer influência da distância dos genótipos já agrupados. Nota-se que tem uma dificuldade em identificar a divergência entre os acessos, visto que a maioria deles se encontra em apenas um grupo.

Tabela 1. Agrupamento de 10 progênies de autofecundação de Physalis angulata por meio do método de Otimização de Tocher, em função da Distância Generalizada de Mahalanobis. UEFS, Feira de Santana, (BA), 2017,

\begin{tabular}{cc}
\hline Grupos & Acessos \\
\hline Grupo I & $1,2,7$ \\
\hline Grupo II & 6 \\
\hline Grupo III & 4 \\
\hline Grupo IV & 8 \\
\hline Grupo V & 10 \\
\hline Grupo VI & 9 \\
\hline Grupo VII & 3 \\
\hline Grupo VIII & 5 \\
\hline
\end{tabular}

Analisando os distintos grupos com suas respectivas distâncias $\left(\mathrm{D}^{2}\right)$ (Tabela 2), é possível identificar as melhores combinações visando cruzamentos genéticos. As maiores distâncias foram observadas entre os acessos 3 e 5 (54,33), 1 e $7(42,83), 5$ e 8 (36,10), 5 e $9(35,33), 2$ e $3(33,31), 2$ e $7(30,81), 1$ e $3(30,58)$ e 2 e $8(29,74)$. Desse modo, os melhores resultados seriam obtidos pela combinação dos acessos integrantes do grupo I, IV, VI, VII e VIII. Valores mínimos de divergência foram encontrados entre os grupos III e V $(0,02)$, II e VI $(0,12)$, I e III $(0,28)$, I e VIII $(0,66)$, III e VIII $(0,87)$, sendo estes acessos os menos indicados para possíveis cruzamentos entre grupos para gerar combinações superiores.

Tabela 2. Distâncias de Mahalanobis ( $\left.\mathrm{D}^{2}\right)$ entre os 10 acessos de autofecundação de Physalis angulata. UEFS, Feira de Santana, (BA), 2017, 


\begin{tabular}{rcrrrrrrrrr}
\hline & 1 & 2 & 3 & 4 & 5 & 6 & 7 & 8 & 9 & 10 \\
\hline 1 & - & 10,76 & 30,58 & 2,29 & 3,99 & 11,89 & 42,83 & 20,85 & 18,12 & 5,48 \\
2 & & - & 33,11 & 5,19 & 1,57 & 23,53 & 30,81 & 29,74 & 18,40 & 9,05 \\
3 & & & - & 23,99 & 54,33 & 18,09 & 18,50 & 2,19 & 4,18 & 21,63 \\
4 & & & & - & 0,87 & 9,14 & 0,28 & 15,86 & 11,82 & 0,02 \\
5 & & & & & - & 25,20 & 0,66 & 36,10 & 35,33 & 1,45 \\
6 & & & & & & - & 23,19 & 9,96 & 0,12 & 5,40 \\
7 & & & & & & & - & 24,41 & 15,73 & 21,67 \\
8 & & & & & & & & - & 20,79 & 17,72 \\
9 & & & & & & & & & - & 9,43 \\
10 & & & & & & & & & & - \\
\hline
\end{tabular}

A contribuição relativa dos caracteres, segundo método de Singh (1981), mostrou que o peso do fruto foi a característica que mais contribuiu com a divergência genética $(49,77 \%)$, seguida do número de frutos $(13,71 \%)$ e diâmetro longitudinal do fruto $(9,78 \%$ ) (Tabela 3). Esses resultados indicam a existência de variabilidade genética significativa para estes caracteres nos genótipos estudados (THIYAGARAJAN et al., 1988). Entretanto, o peso do fruto foi o mais eficiente em explicar a dissimilaridade entre os acessos, devendo ser priorizadas na escolha de progenitores em programas de melhoramento.

Tabela 3. Contribuição relativa dos caracteres para divergência genética nas progênies de autofecundação de Physalis angulata, segundo Singh (1981), utilizando características agronômicas. UEFS, Feira de Santana, (BA), 2017,

\begin{tabular}{cc}
\hline & Progênies \\
\hline Variável $^{1}$ & Valor \\
\hline & $\%$ \\
\hline AP & 2,83 \\
NR & 5,51 \\
NF & 13,71 \\
DC & 7,11 \\
PF & 49,77 \\
DT & 5,43 \\
DL & 9,78 \\
SS & 5,87 \\
\hline
\end{tabular}

${ }^{\mathrm{I}}$ altura da planta (AP), número de ramificações (NR), número de frutos por planta (NFP), diâmetro do caule (DC), peso de fruto (PF), diâmetro transversal do fruto (DTF), diâmetro longitudinal do fruto (DLF) e sólidos solúveis (SS).

O dendograma, obtido a partir da matriz de dissimilaridade gerada a partir das características morfoagronômicas, possibilitou a formação de dois grupos distintos, considerando a proximidade dos acessos entre si, sendo seis indivíduos atribuídos ao grupo I e quatro ao grupo II. O grupo I foi formado pelos acessos 1, 2, 4, 5, 7 e 10. O grupo II foi formado pelos acessos 3, 6, 8 e 9 (Figura 1).

O Coeficiente de Correlação Cofenético do método UPGMA, baseado na distância generalizada de Mahalanobis para os acessos de fisalis ficou abaixo do valor aceitável $(\mathrm{r}=0,58)$. Resultados semelhantes foram encontrados por Cargnelutti Filho et al. (2010), avaliando oito medidas de dissimilaridade e oito métodos de agrupamento de feijão comum gerando coeficientes de correlação cofenética, obtidos a partir das matrizes de distâncias de Mahalanobis, oscilando de 0,59 a 0,88 com média de 0,67, revelando variabilidade na consistência do padrão de agrupamento. Entretanto, deve-se ressaltar que se deve avaliar a magnitude dos valores de CCC sabendo que quanto mais próximos os valores forem da unidade, maior será a consistência do padrão de agrupamento (BARROSO E ARTES, 2003; CRUZ e CARNEIRO, 2003). 


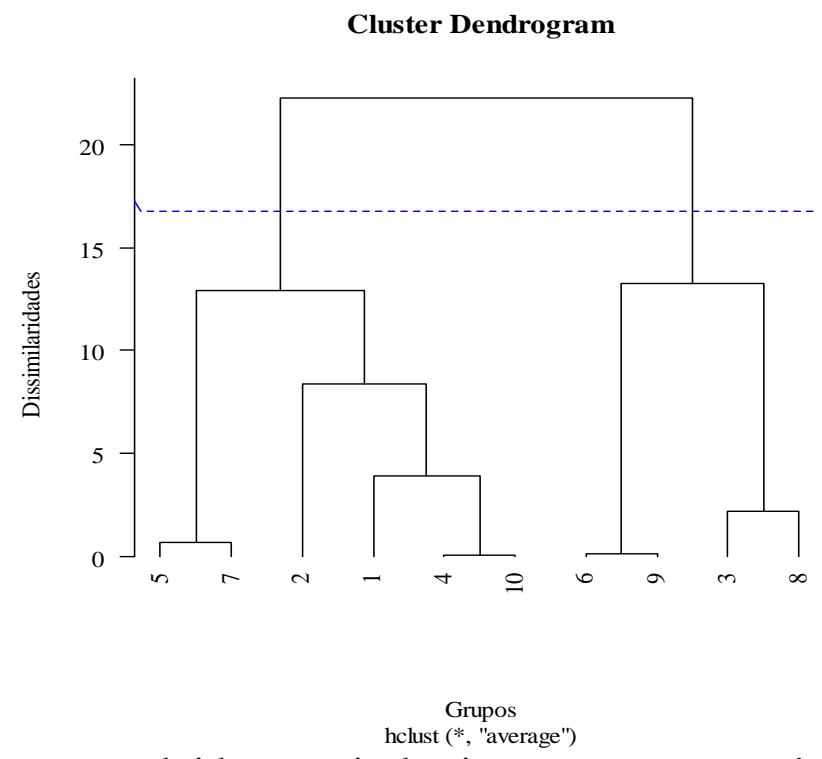

Figura 1. Dendrograma obtido a partir de oito caracteres agronômicos, avaliados em 10 acessos de autofecundação de Physalis angulata, com base nas medidas de dissimilaridade genética obtido pelo método UPGMA.

\section{CONCLUSÕES}

A divergência genética entre os acessos de Physalis angulata indica que existe variabilidade genética. Os melhores resultados seriam obtidos pela combinação dos acessos integrantes do grupo I, IV, VI, VII e VIII, sendo estes cruzamentos o de maior probabilidade em resultar novas combinações gênicas desejáveis para o programa de melhoramento genético. O peso do fruto foi a característica que mais contribuiu com a divergência genética.

\section{REFERÊNCIAS}

CARGNELUTTI FILHO, A.; RIBEIRO, N. D.; BURIN, C. Consistência do padrão de agrupamento de cultivares de feijão conforme medidas de dissimilaridade e métodos de agrupamento. Pesquisa Agropecuária Brasileira, v. 45, n. 3, p. 236-243. 2010. COSTA, F.R.; PEREIRA, T.N.S; SUDRÉ, C.P.;RODRIGUES, R.Marcadores RAPD e caracteres morfoagronômicos na determinação da diversidade genética entre acessos de pimentas e pimentões. Ciência Rural, Santa Maria, v.39,n.3,p.696-704,2009. CRUZ, C. D. E CARNEIRO, P.S.C. Modelos biométricos aplicados ao melhoramento genético. $\quad 585 \quad$ p. 2006. CRUZ, C. D. Programa Genes: Biometria. 585p. 2008. MANTEL, N. The detection of disease clusterin gand a generalize dregression approach. $\begin{array}{llll}\text { Cancer } & \text { Research, } & 27, & 209-220 .\end{array}$ MOJENA, R. Hierárquical grouping method and stopping rules: na evaluation. Computer Journal, $\quad$ v.20, p.359-363, 1977. NASS, L.L.; VALOIS, A.C.C.; MELO, I.S. de; VALADARES-INGLIS, M.C. Recursos genéticos e melhoramento - plantas. Rondonópolis: Fundação MT, 2001. SOKAL, R.R.; ROHLF, F.J. The comparison of dendrograms by objective methods. Taxon, v.11, n.1, $\quad$ p.30-40, 1962. SINGH, S. P.; GUTIERREZ, J. A.; MOLINA, A.; URREA, C.; GEPTS, P. Genetic diversity in cultivated common bean: II. Marker-based analysis of morphological and agronomic traits. $\begin{array}{llllll}\text { Crop } & \text { Science, } & \text { Madison, } & \text { v. } & 31, & \text { p. }\end{array}$ SINGH, D. The relative importance of characters affecting genetic divergence. The Indian

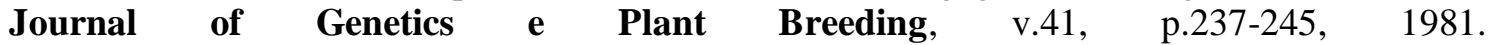
THIYAGARAJAN, K.; NATARAJAN, C. Genetic divergence in cowpea. Tropical Grain $\begin{array}{llllll}\text { Legume Bulletin, } & \text { n. } & 36, & \text { p. } & 2-3, & 1989 .\end{array}$ VASCONCELOS, E. S.; CRUZ, C. D.; BHERING, L. L.; RESENDE JÚNIOR, M. R. F. Método alternativo para análise de agrupamento. Pesquisa Agropecuária Brasileira, v. 42, n. 10, p. 1421-1428, 2007. 